\title{
Cooperative Language Learning: Increasing Opportunities For Learning In Teams
}

Saovapa Wichadee, Bangkok University, Thailand

Wiwat Orawiwatnakul, Bangkok University, Thailand

\begin{abstract}
This paper conceptualizes cooperative language learning, group instruction which is under the learner-centered approach where the groups are formed in such a way that each member performs his or her task to achieve the goal. Previous research indicates that cooperative language learning doesn't only improve learners' language skills, but also create a supportive learning environment. A variety of learning activities is presented, offering new ideas to apply in EFL classes. Although cooperative-based learning produces positive outcomes, some awareness regarding learning process management is raised in order to avoid the problems that might occur during practice.
\end{abstract}

Keywords: Cooperative Learning; Teaching Approach; Classroom Activities

\section{INTRODUCTION: COOPERATIVE LEARNING IN LANGUAGE SETTINGS}

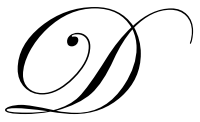

uring the past decade, "cooperative learning" seems to have attracted a lot of attention and became popular. This conceptual approach is based on a theoretical framework that provides general principles on how to structure cooperative learning activities in a teacher's specific subject area, curriculum, students, and setting. It is the one that teachers can use to stimulate students to acquire the knowledge as well as interpersonal and team skills. It helps to promote student-student interaction via working in small groups to maximize their learning and reach their shared goal (Brown: 1994, p.81). As Johnson (2005) puts it, cooperation is not assigning a job to a group of students where one student does all the work and the others put their names on the paper. It is not having students sit side by side at the same table to talk with each other as they do their individual assignments as well. It is not having students do a task individually with instructions that the ones who finish first are to help the slower students. On the contrary, cooperative learning is a teaching strategy in which small teams, each with students of different levels of ability, use a variety of learning activities to improve their understanding of a subject. Each member of a team is responsible not only for learning what is taught but also for helping teammates learn, thus creating an atmosphere of achievement. Students work through the assignment until all group members successfully understand and complete it.

Cooperative learning is characterized by five common elements, including 1) positive interdependence, where the group has a common goal and each member's contribution is important to the group's success; 2) face-toface group interactions in which each member is encouraged to participate, help others succeed, and learn from each other; 3) individual and group accountability in which members divide the work and are individually responsible for specific tasks; 4) development of small group social skills involving negotiating and use of group interaction skills; and 5) group processing, which involves students reflecting on the group's experience (Johnson and Johnson, 1995 cited in Nakahashi, 2007). To be cooperative, group members must promote each other's learning and success faceto-face, hold each other personally and individually accountable to do a fair share of the work, use the interpersonal and small group skills needed for cooperative efforts to be successful, and process as a group how effectively members are working together. These five essential components are needed for small group learning to be truly cooperative.

Cooperative learning has been implemented in many areas including language instruction. Olsen and Kagan (1992) strongly believe that Cooperative Language Learning (CLL) offers a chance for interaction among 
students and helps integrate content learning into language learning. CLL was founded from Dewey's humanistic educational philosophy which supported the notion that learners are the subject of education (Coelho, 1992). CLL will be more efficient if students learn the meaning and function of the language at the same time. Activities and interaction among group members emphasize communicative skill, promoting them to practice language usage in various situations. Since CLL provides students with an opportunity to be responsible for learning, as well as helping one another to reach the goal, the supportive environment is meaningful to language learners (Yeh, 2008). Basically, CLL is suitable to be used in the Thai education system because it serves the National Education Act (1999) with two main reasons. The first one is that this learning context emphasizes cooperation in helping each other to acquire knowledge. Cooperative learning activities have been employed with EFL students due to the fact that they can foster active participation, a sense of community, emotional support and provide more social interaction for students. This type of learning decreases competitiveness and individualism but increases opportunities to actively construct or transform the knowledge among students. Second, CLL creates studentcenteredness. As we know, teacher-centered approaches taking place in traditional classroom could not produce active recipients and resulted in fossilized language learning. It is not effective enough to promote language acquisition. Interaction among group members, therefore, is believed to produce communicative skills, enabling students to practice language skills in various situations.

\section{RESEARCH SUPPORT FOR COOPERATIVE LANGUAGE LEARNING}

A number of research studies on cooperative-based learning in all levels of education have been conducted, with most of them yielding positive results for a variety of cognitive and affective outcomes. Analyses of the research can be drawn to the following conclusions:

\section{The Effect On Students' Social Relationship}

Three pieces of research demonstrate that cooperative learning produced more positive social relationships among students (Scaglion, 1992; Du, 1998; Chen, 1998).

\section{The Effect On Students' Learning Achievement}

The results of three studies showed that the post-test scores, after learning English reading using cooperative learning, were higher than the pre-test scores at the .05 level of significance. Most of the samples displayed very good behavior in cooperating in their tasks (Tang, 2000; Seetape, 2003; Wichadee 2005).

\section{The Effect On Students' Critical Thinking Skills}

A study was conducted to compare critical thinking skills of students who studied Business English I at Chiangrai Commercial School using the cooperative learning method with those of students using the traditional group work method. The post-test scores of students who were taught through the cooperative learning method were remarkably higher than the post-test scores of students who were taught through the traditional group work method at $\mathrm{p}<.05$ level. Moreover, the unit post-test scores of the experimental group were higher than those of the control group as the statistical difference was significant at $\mathrm{p}<.05$ level. The results of the questionnaire showed that students' opinions toward the cooperative learning were moderately positive (Somapee, 2002).

\section{The Effect On Students' Self-Efficacy}

A study examined the effects of cooperative learning using Student Team-Achievement Divisions (STAD) technique on self-efficacy. Results indicated that the students who studied through STAD had a higher self-efficacy after the treatment than before the treatment at the .01 level of significance. The students who studied through STAD had higher self-efficacy and English learning achievement than those students who studied through the conventional method at the .01 level of significance (Moryadee, 2001). 


\section{The Effect On Students' Learning Anxiety And Language Proficiency}

One study was done to examine the effectiveness of cooperative learning approach in reducing foreign language anxiety and to investigate its impact on language proficiency of 40 sophomore students enrolled in EN 211 course in the second semester of academic year 2009 at Bangkok University. Three instruments employed were the standardized Foreign Language Classroom Anxiety Scale (FLCAS) (Horwitz, Horwitz, \& Cope, 1986), two proficiency tests covering reading and writing skills, and a semi-structured interview. The pre- and post- scores from the questionnaire and the tests of the group were calculated for descriptive statistics and compared using a paired sample t-test measure. It was found that the students' top five sources of language classroom anxiety and overall language anxiety were significantly decreased. In addition, they obtained higher language proficiency scores for the post-test than the pretest at the significance level of .001 after learning through this approach. The students also had a favorable attitude toward cooperative learning as a whole (Suwantarathip \& Wichadee, 2010).

\section{CREATING COOPERATIVE LANGUAGE LEARNING (CLL) ACTIVITIES}

Macpherson (2009) states that cooperative learning is a very formal way of structuring activities in a learning environment which includes specific elements intended to increase the potential for rich and deep learning of the participants. So, the appropriate cooperative learning models for language settings should be designed based on the following basic principles:

- $\quad$ Group tasks are designed to be suitable for group work.

- $\quad$ Positive interdependence is built in - cooperation is necessary for students to succeed.

- $\quad$ Attention and class time are given to interpersonal/cooperative skill building.

- $\quad$ Participants learn together in small (2-5 members) groups.

- $\quad$ Students are individually accountable for learning and participation.

- The instructor's role changes from being the "sage on the stage" to the "guide on the side".

Although there are many types of cooperative learning activities implemented in EFL class, four main activities are suggested as they provide more channels for students to get knowledge and information. These activities are not at all anxiety-provoking situations, but increase supportiveness among students.

The first activity "Think-Pair-Share", developed by Frank Lyman and his colleagues in Maryland, can be used to encourage student classroom participation without stress. This activity helps the students to formulate individual ideas and share these ideas with another student. It involves a three-step cooperative structure. In the "think" step, the teacher provokes students' thinking with a question or a prompt. It should take a few moments for them to think about the question individually. In the "pair" step, students work in pairs talking about the answer each comes up with. They compare their written notes and identify the answers they think are best, most convincing or most unique. In the last step called "share", the teacher calls for pairs to share their thinking with other pairs and the rest of the class. Often, the teacher or a designated helper will record these responses on the board. Students are allowed to choose their own partners in doing pair work (Lyman, 2002). This kind of activity covers different tasks and can be created to improve different skills as follows (Instructional Strategies Online, 2009):

- $\quad$ Think-Write-Pair-Share - To increase individual accountability, have students jot down their ideas before turning to a partner to discuss them. The teacher can walk around the room and look at what they are writing to see who understands the concept. It also prevents students from adopting their partner's attitude easily or just sitting back and letting their partner do all the thinking.

- $\quad$ Spelling - The teacher calls out a word, has them think of the spelling, then designates one person to turn and whisper the spelling to their partner. The partner gives a thumbs-up to show agreement or corrects the spelling. The teacher can reveal the correct spelling by showing it on screen with PowerPoint.

In short, think-Pair-Share provides an opportunity for all students to share their thinking with at least one other student, which, in turn, increases their sense of involvement in classroom learning. 
The second group work activity the teacher can employ is "Numbered Heads Together." Its structure is derived from the work of Spencer Kagan (2003). A team of four is established and each member is given numbers of $1,2,3,4$. Questions are asked of the group whose members work together so that all can verbally answer the questions. The teacher calls out a number and that number in each team is asked to give the answer. By doing this, everyone in the team must participate and be able to answer the question. This activity is usually conducted to enhance students' reading comprehension skill. One great benefit includes students being able to learn from each other. They must work together to ensure that everyone can understand and answer the question. This activity is one way to reduce anxiety in class.

The third activity is called "Circle the Sage" created by Kagan (1994). First, the teacher polls the class to see which students have a special knowledge to share. For example, the teacher may ask who in the class was able to solve a difficult math homework question, who had visited Mexico, who knows the chemical reactions involved in how salting the streets help dissipate snow, etc. Those students (the sages) stand and spread out in the room. The teacher then has the rest of the classmates surround a sage, with no two members of the same team going to the same sage. The sage explains what they know while the classmates listen, ask questions, and take notes. All students then return to their teams. Each, in turn, explains what they learned. Because each one has gone to a different sage, they compare notes. If there is disagreement, they stand up as a team. Finally, the disagreements are aired and resolved.

The last activity, which fits the learner-centered approach, is called "Peer Review" - an activity requiring students to read each other's draft and give comments on it. "Peer Review" provides students with the opportunity to learn how to give and receive constructive feedback. The main goal of using peer review is to help both writers and commentators improve their writing. The benefits from doing peer feedback are that 1) students who give feedback to peers will develop their critical thinking and 2) students will become active learners (Villamil \& Guerrero, 1998). The peer review is usually conducted in pairs. The students are trained on the principles of peer correction and how to give feedback so that they would not encounter any difficulties when giving comments. Peer review training should be available before the lesson officially starts. This means they will be taught how to follow the review procedure step by step, how to consult the dictionary when in doubt, how to write up a comment, etc. Through peer review activity, students will experience supportive peer feedback which helps to increase their motivation and attitude toward studying English. The feedback from peers is less threatening than from teachers, so there is less anxiety in class.

\section{EVALUATION USED IN COOPERATIVE LANGUAGE LEARNING}

One problem of students' unwillingness to do cooperative learning is due to the grading. Low-achievers might learn harder, but high achievers might lose motivation when evaluation is done as a whole or as a group. Therefore, to encourage both groups to learn in order to make good progress, teachers should not only assess students' learning achievement by groups, but also evaluate them individually. Oxford (1997) proposes that teachers should grade students on how they improve, even though they are assigned to four-member learning teams that are mixed in performance level. During team study, group members may work cooperatively with provided worksheets and answer sheets. The function of the team is to prepare its members to do well on the quizzes. However, after one or two periods of team practice, each student individually takes a quiz on the material. Students are not permitted to help one another during the quizzes. Next, the teacher scores the papers using a scoring system that ranges from 0 to 30 points and reflects degree of individual improvement over previous quiz scores. That is, students' quiz scores are compared with their own past averages. Slavin (1995) used the following scoring procedure to stimulate students' learning in STAD model:

Step 1: Establishing base line (Each student is given a base score based on an average on past quizzes.)

Step 2: Finding current quiz score (Students receive points for the quiz associated with the current lesson.)

Step 3: Finding improvement score (Students earn improvement points to the degree in which their current quiz score matches or exceeds their base score, using the scale provided.) 


\section{Quiz score}

More than 10 points below base score

10 points below to 1 point below base score

Base score to 10 points above base score

More than 10 points above base score

Perfect paper (regardless of base score in Step 1)

\section{Improvement Points}

0

10

20

30

30

The purpose of base scores and improvement points is to make it possible for all students to bring maximum points to their teams, whatever their level of past performance. It is fair to compare each student with his or her own level of past performance since all students enter a classroom with different levels of skills and experience in English. Therefore, whenever CLL takes place in class, students tend to have a positive attitude toward it.

\section{ADVANTAGES OF COOPERATIVE LANGUAGE LEARNING}

Cooperative language learning is a good solution to any instructional problem. It is believed to be one of the best approaches as it promotes students to work in teams with cooperation to accomplish something of importance. Based on the author's experience of facilitating CLL in many classes, students developed themselves a lot in different aspects.

\section{The Increase In Motivation But Less Competition On Studying}

A CLL class, compared with a teacher-centered class, is likely to be more beneficial in terms of producing supportive relationships among students. Therefore, cooperative learning can change students' learning behavior. Although some students are not concerned about grades or interested in participating in class, if a group's performance depends on each individual contributing, they have to come. They don't want to miss a class in which all assignments are handed out and they don't want to disappoint their teammates since they care about their peers. They know that members cannot work without them. Although some students are not much concerned about grades, they don't want to fail their group by missing the points from the quiz. That is, cooperative learning can dramatically improve students' attendance as well as motivation to learn.

\section{Students' Development In Thoughts}

All members have a chance to think about the issues or problems that the teacher raises; they have a chance to discuss and determine the answer for the group. This can maximize the students' interaction in English and it can take away the big burden of running large classes. It solves the problem that one teacher cannot pay attention to all students. With this method, they receive attention not only from the teacher, but also from their friends.

\section{Better Perception On Other Group Members' Intention}

When working together, each student can see how much effort their team members are making. Students possess a sense of community. Cooperative learning can solve the problems of isolation and alienation that are two predictors of failure. According to Tinto (1994), two main reasons for dropping out of university are failure to establish a social network of friends or classmates and failure to become academically involved in classes.

\section{Reducing Students' Learning Anxiety}

Cooperative learning provides a less anxiety-producing context in terms of discussing, creating, and thinking in a group rather than in a whole class. In such an atmosphere, students may feel more comfortable studying and trying out new ideas. Normally, students tend to be silent when they do not want to clarify their confusion. This concept is in accordance with Wei (1997) who demonstrates that speaking to a whole class is often a threatening experience to most students, but they are quite at ease talking to their group members. Further interaction occurred in group discussion and peer checking of worksheets since students exchange ideas and make corrections or improvements in collaboration instead of individual learning. Language acquisition can occur in a 
context that is supportive, friendly, motivating, communicative, developmentally appropriate, and feedback rich (Kagan,1994).

\section{PUTTING SOME AWARENESS ON COOPERATIVE LANGUAGE LEARNING}

Nowadays, cooperative language learning is employed in different parts of the world to enable active learning. The reason behind the frequent use of it is that this kind of learning offers a lot of opportunities for students to improve themselves in different aspects, such as knowledge, skill, attitude, and achievement as mentioned earlier. Although most research results offer positive perspectives of cooperative learning, some awareness should be taken into consideration when implementing it in language teaching. Based on the author's experience, most of the limitations of cooperative learning came from not being able to implement the cooperative structure completely. First, it is time-consuming for students to learn materials in a cooperative way and to work together in groups. This might affect other contents which teachers need to cover. Therefore, teachers should be aware of time limitation in order to make group learning more meaningful. The class activities should be wellplanned in advance to ensure the learning process is really based on cooperative learning. Second, the room with fixed chairs might not be suitable for doing cooperative learning activities. Also, the seats arranged in tiers and spaces narrowly apart make it difficult for group working. Third, CLL will never take place if student don't get clear instructions, so students have to be informed of what they are doing. They should be told what it is they are going to learn and why it is important so that they will realize they must pay careful attention during the class presentation because doing so will help them to do well on the quizzes which determine their team scores. They are obliged to help their members learn. After the material is presented by the teacher, the team meets to study worksheets or other material. Most often, they have to discuss the problems together, compare answers, and correct any misconceptions if teammates make mistakes. Lastly, most Thai students feel uncomfortable speaking English to their friends; for this reason, they do not take advantage of the chance to do so. To solve this problem, students should be encouraged to interact and converse with one another in English in order to practice the target language and absorb knowledge. Moreover, it will be better to have them prepare themselves or study the content in advance.

\section{AUTHOR INFORMATION}

Assoc. Prof. Saovapa Wichadee is now working as a full-time lecturer at the Language Institute, Bangkok University, Thailand. Her research interest includes teaching methodology in EFL, learners' characteristics, and teacher self-development. She has experienced in writing many textbooks and instructional materials, such as Writing for Business Purposes, English for Art and Design, and Business Conversation. E-mail: saovapa.w@bu.ac.th. Corresponding author.

Wiwat Orawiwatnakul is currently a full-time lecturer at the Language Institute, Bangkok University, Thailand. His research interest lies in improving students' reading skills as well as increasing vocabulary knowledge through a variety of learning techniques. E-mail: wiwatt48@ hotmail.com.

\section{REFERENCES}

1. Brown, H. (2004). Principles of language learning and teaching. Englewood Cliffs, NJ: Prentice Hall.

2. Cheng, W. (1998). How effective is group work as an aid to L2 learning? Journal of Fushin Institute of Technology, 411-15.

3. Coelho, E. (1992). Cooperative learning: foundation for communicative curriculum. In C. Kessler (Ed.) Cooperative Language Learning: A Teacher's Resource Book. Englewood Cliffs, NJ: Prentice Hall.

4. Du, S. (1998). The effects of cooperative learning on adult English learning achievement, behavior, and satisfaction. Master's thesis: National Chung Cheng University.

5. Horwitz, E. K., Horwitz, M. B., \& Cope, Jo Ann. (1986). Foreign language classroom anxiety. The Modern Language Journal, 70 (2), 125-132.

6. Instructional Strategies Online. (2009). What is think pair share? Retrieved November 14, 2010, from http://olc.spsd.sk.ca/DE/PD/instr/strats/think/.

7. Johnson, D. (2005). Cooperative learning: Increasing college faculty instructional productivity. Retrieved February 15, 2009, from http://www.ntlf.com/html/lib/bib/92.2dig.htm. 
8. Johnson, D. W., Johnson, R. T., \& Holubec, E. J. (1995). Circles of learning. (4th ed.). Edina, MI: Interaction Book Company.

9. Kagan, Spencer. (1994). Cooperative learning. CA: Kagan Publishing.

10. (2003). A Brief history of Kagan structures. Kagan Online Magazine. Retrieved October 12 , 2010, from http:// www.kaganonline.com/KaganClub/FreeArticles.

11. Kondo, S. \& Yang, Y-L. (2003). The English language classroom anxiety scale: Test construction, reliability and validity. JALT Journal, 25 (2), 14-16.

12. Lyman, F. (2002). Strategies for reading comprehension think-pair-share. Retrieved October 12, 2010, from http://www.readingquest.org/strat/tps.html.

13. MacIntyre, P. D. (1995). How does anxiety affect foreign language learning: A reply to Sparks and Ganschow. The Modern Language Journal, 79(1), 90-99.

14. Macpherson, A. (2009). Cooperative learning group activities for college courses: A guide for instructors. Retrieved October 25, 2009 from www.kwantlen.ca/academicgrowth/resources/CoopLearningActivities.doc.

15. Melvin, A. \& Kenneth, W. (2009). Foreign language learning anxiety in Japanese EFL university classes: Physical, emotional, expressive, and verbal reactions. Sophia Junior College Faculty Journal, 29, 1-24.

16. Moyadee, W. (2001). Effects of cooperative learning using student teams-achievement division technique on self-efficacy and English learning achievement of prathomsuksa five students. Master's thesis, Chulalongkorn University.

17. Nakahashi, Terri Lee. (2007). Techniques for reducing foreign language anxiety: Results of a successful intervention study. Retrieved August 12, 2010, from http://air.lib.akitau.ac.jp/dspace/bitstream/ 10295/547/3/kk9-6.pdf.

18. Olsen, R. \& Kagan, S. (1992). About cooperative learning. In C, Kessler (Ed.), Cooperative Language Learning (pp.1-30). Englewood Cliffs, NJ: Prentice Hall.

19. Scaglion, J. (1992). Cooperative learning strategies in the business education curriculum. Business Education Forum, 46 (4), 15-17.

20. Seetape, N. (2003). Effects of cooperative learning on English reading achievement and learning behaviors of mathayomsuksa three students in Kanchanaphisek Wittayalai Uthaithani School. Master's thesis, Kasetsart University.

21. Slavin, R. (1995). Cooperative learning: Theory, research, and practice. Massachusetts: Allyn and Bacon.

22. Somapee, S. (2002). The effectiveness of using cooperative learning to enhance students' critical thinking skills in Business English I at Chiangrai Commercial School in Chiangrai. Master's thesis, Payap University.

23. Suwantarathip, O. \& Wichadee, S. (2010). The impacts of cooperative Learning on anxiety and proficiency in an EFL class. The Journal of college teaching and learning. 7(11), 51-57.

24. Tang, H. (2000). Using cooperative concept mapping skill to teach ESL reading. PASSA, 30, 77-89.

25. Tinto, V. (1994). Leaving college: Rethinking the causes and cures of student attrition (2 ${ }^{\text {nd }}$ ed.). Chicago, IL:University of Chicago Press.

26. Villamil, O.S. \& Guerrero, M.C. (1998). Assessing the impact of peer revision on L2 writing. Retrieved July 26, 2007, from http://applij.oxfordjournals.org/cgi/reprint/.

27. Wei, C. (1997). Union is strength: Applications of cooperative learning to college EFL class in Taiwan. Taipei, Taiwan: Crane.

28. Wichadee, S. (2005). The effects of cooperative learning on English reading skill and attitudes of the firstyear students at Bangkok University. BU Academic Review. 4(2) July-December, 22-31.

29. Worde, R. (2003). Students' perspectives on foreign language anxiety. Retrieved March 4, 2010, from http://www.vccaedu.org/inquiry/inquiry-spring2003/i-81-worde.html.

30. Yeh, Ann Tsu. (2008). Learners' anxiety and behaviors in a cooperative language learning classroom. Master's thesis. Ming Shuan University.

31. YU-ching, Daniel, \& Wu, Guo-cheng. (2004). A Study of foreign language anxiety of EFL elementary school students in Taipei. County Journal of National Taipei Teachers College, 17(2), 287-320. 
NOTES 